\title{
Optical biopsy of epithelial cancers by optical coherence tomography (OCT)
}

\author{
R. Wessels • D. M. De Bruin • D. J. Faber • \\ T. G. Van Leeuwen • M. Van Beurden • T. J. M. Ruers
}

Received: 31 January 2013 / Accepted: 19 February 2013 /Published online: 16 March 2013

(C) The Author(s) 2013. This article is published with open access at Springerlink.com

\begin{abstract}
Optical coherence tomography (OCT) is an optical technique that measures the backscattering of near-infrared light by tissue. OCT yields in $2 \mathrm{D}$ and $3 \mathrm{D}$ images at micrometer-scale resolution, thus providing optical biopsies, approaching the resolution of histopathological imaging. The technique has shown to allow in vivo differentiation between benign and malignant epithelial tissue, through qualitative assessment of OCT images, as well as by quantitative evaluation, e.g., functional OCT. This study aims to summarize the
\end{abstract}

R. Wessels and D. M. De Bruin contributed equally to this paper.

R. Wessels $(\bowtie)$

Department of Surgical Oncology,

Netherlands Cancer Institute-Antoni van Leeuwenhoek Hospital, PO Box 90203, Amsterdam 1006 BE, The Netherlands

e-mail: ronniwessels@gmail.com

T. J. M. Ruers

Department of Surgical Oncology,

Netherlands Cancer Institute-Antoni van Leeuwenhoek Hospital, Plesmanlaan 112,

Amsterdam 1066, The Netherlands

D. M. De Bruin • D. J. Faber • T. G. Van Leeuwen

Department of Biomedical Engineering \&Physics,

Academic Medical Center, Amsterdam, The Netherlands

D. M. De Bruin

Department of Urology, Academic Medical Center, Amsterdam, The Netherlands

T. G. Van Leeuwen

Biomedical Photonic Imaging Group, University Twente,

Enschede, The Netherlands

M. Van Beurden

Department of Gynaecologic Oncology,

Netherlands Cancer Institute-Antoni van Leeuwenhoek Hospital, Amsterdam, The Netherlands

T. J. M. Ruers

Nanobiophysics Group and MIRA Institute, University Twente, Enschede, The Netherlands principles of OCT and to discuss the current literature on the diagnostic value of OCT in the diagnosis of epithelial (pre) malignant lesions. The authors did a systematic search of the electronic databases PubMed and Embase on OCT in the diagnostic process of (pre)malignant epithelial lesions. OCT is able to differentiate between benign and (pre)malignant lesions of epithelial origin in a wide variety of tissues. In this way, OCT can detect skin cancers, oral, laryngeal, and esophageal cancer as well as genital and bladder cancer. OCT is an innovative technique which enables an optical biopsy of epithelial lesions. The incorporation of OCT in specific tools, like handheld and catheter-based probes, will further improve the implementation of this technology in daily clinical practice.

Keywords Optical coherence tomography $\cdot$ Epithelial cancers $\cdot$ Imaging

\section{Introduction}

More than $80 \%$ of all cancers originate from the epithelium [1]. Current methods of diagnosing these cancers rely on histological and cytological examination of tissue or body fluids. For this purpose, brushes or biopsies are harvested, which have to be fixed and stained before diagnosis. To circumvent this time-intensive procedure, new optical imaging modalities that enable real-time (pre)malignant lesions detection in vivo are being investigated at the moment. Optical coherence tomography (OCT) is a technology developed in the early 1990s for ophthalmological applications $[2,3]$ and is profoundly used in that setting. OCT is the optical equivalent of ultrasound, using light instead of sound, to produce images of tissue. Resolutions up to $1-2 \mu \mathrm{m}$ can be achieved, being 100-250 times higher than high-resolution ultrasound [4] and approaching that of microscopy. However, due to light scattering by the sample, imaging depth is usually limited to $\sim 2 \mathrm{~mm}$. An image produced by OCT resembles the tissue 
architecture observed in histology and can therefore be considered as an "optical biopsy". This "optical biopsy" has high potential in epithelial tumor diagnosis as it is non-invasive and real-time [4]. Moreover, functional quantitative information can be extracted, i.e., flow information, layer thickness, and attenuation coefficient of the OCT signal $[5,6]$. Given the match between OCT imaging and histology in epithelial tissues, OCT can play an important role in the diagnosis of tumorous lesions.

After our pioneering work in kidney cancer [7, 8], bladder cancer [9], and premalignant vulvar intraepithelial neoplasia [10], we aim to review the diagnostic potential of OCT in (pre)cancerous lesions of the human epithelium. As most investigators study qualitative OCT, we focus on qualitative, morphological imaging of human epithelium, especially of the skin, the oropharyngeal and laryngeal area, the esophagus, the genital area, and the bladder. At the end, we focus on quantitative, e.g., functional OCT and we outline the potential future application of functional OCT imaging in diagnosing (pre)cancer.

\section{Background of technique}

OCT is based on depth resolved detection of elastic light scattering. When light is directed at a tissue sample, it will be partially back scattered. This back-scattered light is measured at different depths at a particular location on the tissue using low-coherence interferometry resulting in a reflection profile in the depth $\left(z^{-}\right)$direction. The magnitude of the OCT signal at each depth is determined by the different cellular structures in the imaged volume (typically in the order of $10^{3} \mu \mathrm{m}^{3}$ or $1 \mathrm{pl}$ ) and as a result it differs per tissue type. Several adjacent depth profiles can be acquired in the lateral $(x-)$ direction and displayed as a gray-scale image in real time which is known as an OCT B scan. Subsequently, the OCT beam can be scanned across a tissue sample in the other lateral $(y-)$ direction, resulting in a 3D image representation with acquisition speed reported up to several volumes per second.

\section{System setup}

The OCT system (Fig. 1) consists of an interferometer, generally constructed from fiber optic components, illuminated by a broad wavelength-range light source operating in the nearinfrared (typically $1,250-1,350 \mathrm{~nm}$ for non-ophthalmic applications). A small fraction of the light is guided towards a "reference" mirror; the majority is directed to the tissue, using handheld XY-scanning devices or miniaturized endoscopic probes (Fig. 2). Both fractions are combined and directed towards a detection unit and subsequent computer processing. Disposable in vivo OCT probes with a diameter less than $1 \mathrm{~mm}$ are developed and already used in several medical settings, enabling OCT to be used in endoscopes or in combination with $16 \mathrm{G} / 18 \mathrm{G}$ needles to access internal tissue. Clinical value of OCT images depends on obvious factors such as high resolution, high-imaging speed, and adequate contrast to discriminate between benign and malignant tissues.

Contrast in OCT is caused by spatial differences in refractive index of different tissue constituents, e.g., contrast originates from reflection of different structures. It is known that the refractive index is proportional to the density of the cells and cell structure. Because malignant cells display an increased number, larger and more irregularly shaped nuclei with a higher refractive index and more active mitochondria, OCT images are expected to be different in malignant tissue compared to normal and benign tissue [11].

\section{Methods}

For this systematic review, we performed a literature search using PubMed and Embase for original and review articles
Fig. 1 Schematic overview of the OCT system. An optical beam (from the light source) is split into two arms. One arm is directed at the tissue (scanning sample arm), the other at a mirror (the reference arm). The reflected light from these two paths is recombined and the differences between these two paths can be shown in a greyscale image

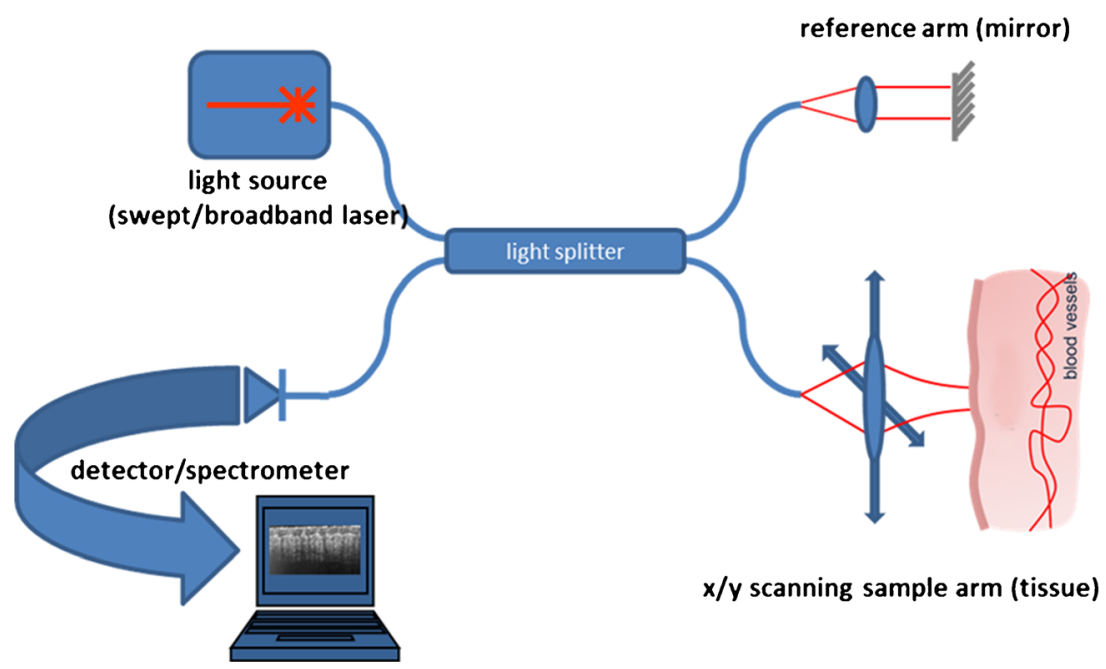




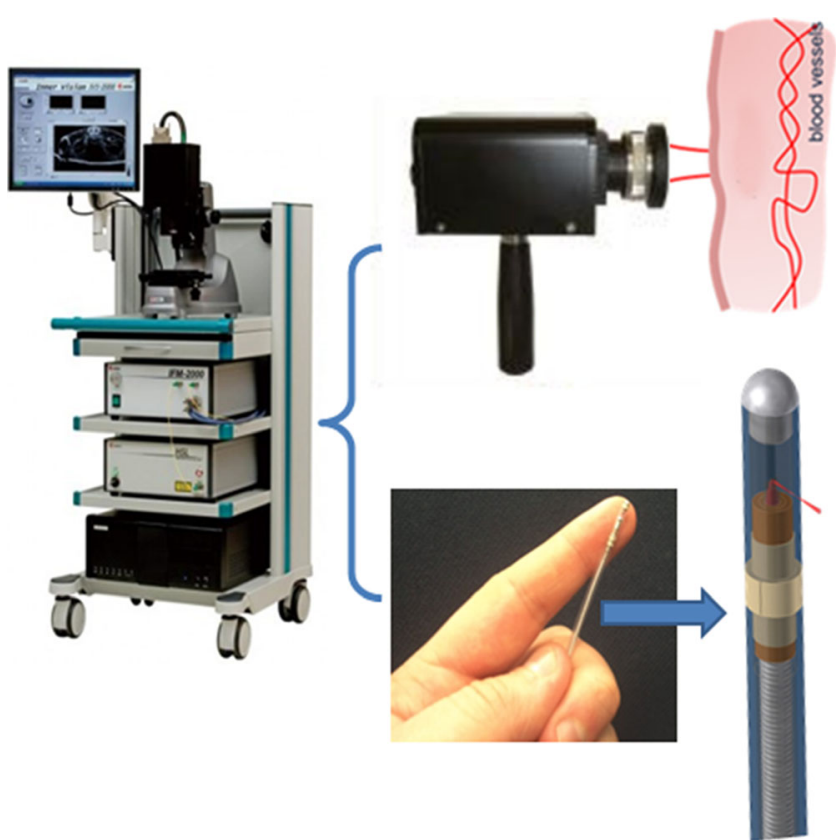

Fig. 2 Clinical OCT system employed at our medical center. Left shows the system on a cart allowing the system to be transferred from different clinical settings easily. The system can be interfaced with either an $x / y$ scanning handheld device (upper right) or a rotating endoscopic scanning device (lower right). The latter scans its environment by fast rotational (lighthouse like) movements. 3D imaging in this case is achieved by a pullback of the probe

written in English, French, or German using the search terms optical coherence tomography and skin cancer or melanoma (rendering 85 and 16 articles, respectively), optical coherence tomography and oral, pharyngeal, or laryngeal cancer (rendering 30 and 8 articles, respectively), optical coherence tomography and esophageal diseases (rendering 74 and 27 articles, respectively). Optical coherence tomography and urinary bladder, vulvar, cervical, or penile cancer (rendering 95 and 42 articles, respectively) This search resulted in a total of 377 hits, from which we selected 57 articles based on relevant contribution in describing technology and clinical evaluation of these methods in skin cancer, oral, laryngeal and esophageal cancer and genital and bladder cancer. Selected articles originated from 1991 to 2012.

\section{Results}

Skin cancer

\section{Nonmelanoma skin cancer}

Nonmelanoma skin cancer (NMSC), including basal cell carcinomas (BCC), squamous cell carcinomas (SCC), and the premalignant actinic keratosis (AK), is the most prevalent cancer in light-skinned populations [12]. OCT could benefit the diagnostic management of NMSC, especially in patients with multiple lesions or lesions at locations where resection results in bad cosmetic outcome [13].

Several studies are performed to assess whether OCT is useful in diagnosing tumors and defining tumor borders [14-20]. Olmedo et al. investigated 27 patients with BCC. In 20 of them, the OCT images matched with histopathology. A typical OCT image of BCC is shown in Fig. 3a. In these images, the dark lobules representing BCC appeared as a reflection density of the epidermis. A decreased reflectance was seen around the periphery of the lobules of the tumor, while the fibrous stroma closely surrounding the BCC showed increased intensity. For the seven specimens that did not match, technical issues had interfered with the examination [18]. Gambichler et al. imaged BCC as well as healthy skin. In OCT images, healthy skin showed layered skin architecture, whereas BCC showed loss of these layers and disarrangement of the epidermis and dermis [14]. Absence of welldefined layering in NMSC has been seen by others as well $[16,20]$. Mogensen et al. compared OCT directly to the accuracy of pathology diagnosis. Depending on the observers, sensitivity and specificity varied from 57 to $94 \%$ and 43 to $96 \%$, respectively. Experienced observers reached a sensitivity of 79 to $94 \%$ and a specificity of 85 to $96 \%$ [16]. Instead of observing the OCT images, Jorgensen et al. implemented a machine-learning analysis. Correct classification of $37 \mathrm{AK}$ lesions and $41 \mathrm{BCCs}$ compared to pathology were made with an accuracy of $73 \%$ (AK) and $81 \%$ (BCC) [15]. Other studies focused on measuring the thickness of BCC [19] and AK [17] in vivo. A strong correlation between tumor thickness measured in both OCT and pathology was found $(p<0.001)$ [19]. Overall, OCT is able to show the different skin layers and is capable to measure tumor thickness in NMSC.

\section{Malignant melanoma}

In case of a malignant melanoma (MM), thickness is the most important factor for (a) staging, (b) determining the size of the excision margins, and (c) the need for sentinel lymph node biopsy. Using OCT to measure MM thickness could enable better preoperative planning by defining resection margins and the need for sentinel lymph node biopsy. Moreover, a non-invasive diagnostic tool capable of distinguishing between benign nevi (BN) and $\mathrm{MM}$ would decrease the amount of unnecessary harvested biopsies and excisions. Histopathologically, MM consists of atypical melanocytes (with atypical nuclei and nucleoli) that invade the epidermis and sometimes even invade the dermis. These atypical cells may have a different nuclear refractive index and thus lead to difference in scattering [11]. A typical OCT image of MM is shown in Fig. $3 b$. 
a

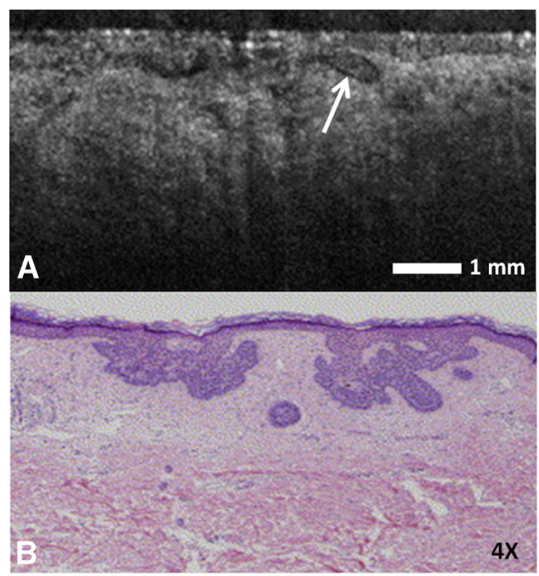

b
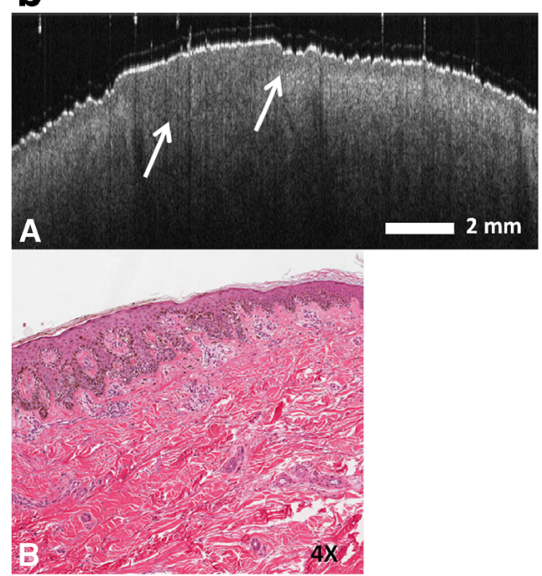

C

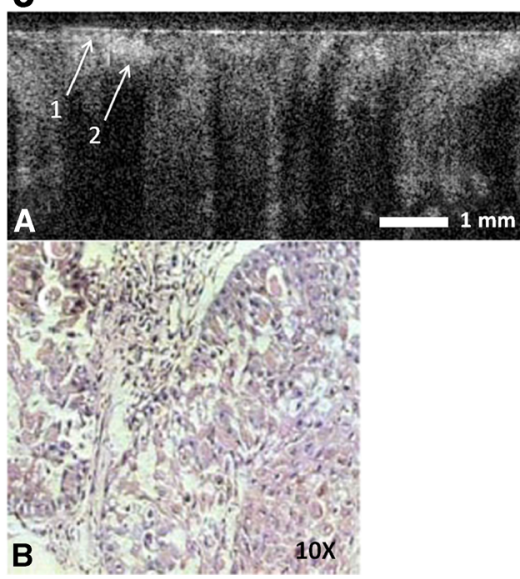

Nodular basal cell carcinoma over the scapula.

A, OCT image and B, corresponding histologic section showing basaloid islands (arrow in A) extending from the epidermis.[18]

Reprinted from [18], with permission from Elsevier.

Superficial spreading melanoma on the back.

A, OCT image and B, corresponding histologic section showing superficial spreading melanoma (arrow in A) extending from the epidermis.

Alveolar ridge with squamous cell carcinoma.

A, OCT image and B, corresponding histologic section showing keratinized epithelial surface layer (arrow 1 in $\mathbf{A}$ ) and stratified squamous epithelium (arrow 2 in A). [24]

This material is reproduced with permission of John Wiley \& Sons, Inc.

Fig. 3 OCT vs. histology of several epithelial lesions

Only a few studies are performed to investigate whether OCT is useful in detecting MM. De Giorgi et al. studied the pigment network and brown globules in melanocytic pigmented lesions as seen with dermatoscopy [21] and compared these features with OCT and histology. In 6 out of 10 cases, it was possible to compare structures found in dermatoscopy and histology to structures in OCT. However, it was impossible to differentiate MM from BN. On contrary, a

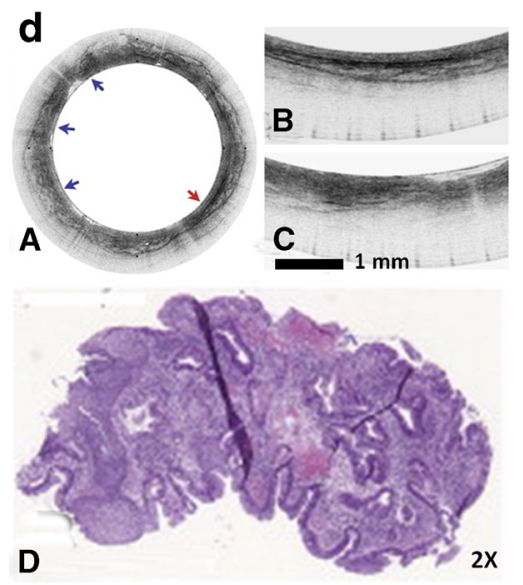

Barrett's esophagus.

A Cross-sectional OCT image reveals both the normal layered appearance of squamous mucosa (red arrow, expanded in $\mathbf{B}$ ) and tissue that shows specialized intestinal metaplasia(blue arrows, expanded in C) D Histologic section corresponding to C. [36]

Reprinted from [36], with permission from Elsevier.

\section{e}

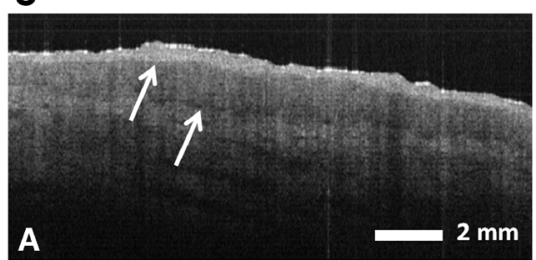

VIN lesion.

A, OCT image of a VIN esion, chareacterized by a thickened epithelial layer and $\mathbf{B}$, corresponding histologic section.
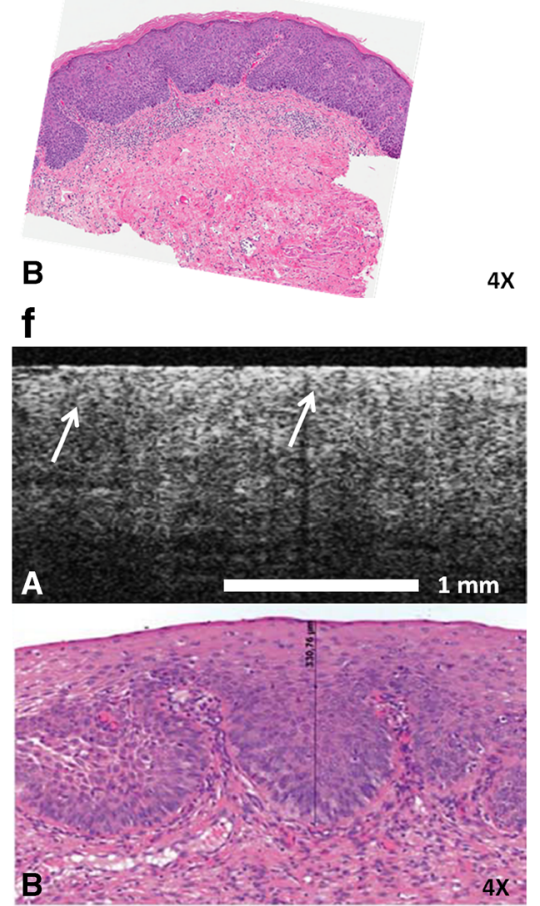

CIN I lesion.

A, OCT image and $\mathbf{B}$, corresponding histologic section, characterized by an increasing irregularity of the epithelial

layer and the optical appearance of vertical columns pushing towards the surface (arrows).[42]

This material is reproduced with permission of John Wiley \& Sons, Inc. study by Gambichler et al. showed significant differences in OCT imaging of BN and MM [22]. A total of 75 patients with $52 \mathrm{BN}$ and $40 \mathrm{MM}$ were included. MM showed a marked architectural disarray $(p=0.036)$ and rarely displayed a clear dermo-epidermal border $(p=0.0031)$ when compared to $\mathrm{BN}$. The most prominent OCT feature of MM was large, vertical cone-shaped structures, which were not observed in $\mathrm{BN}$ $(p<0.001)$ [22]. Although these results are promising, a large 


\section{g}

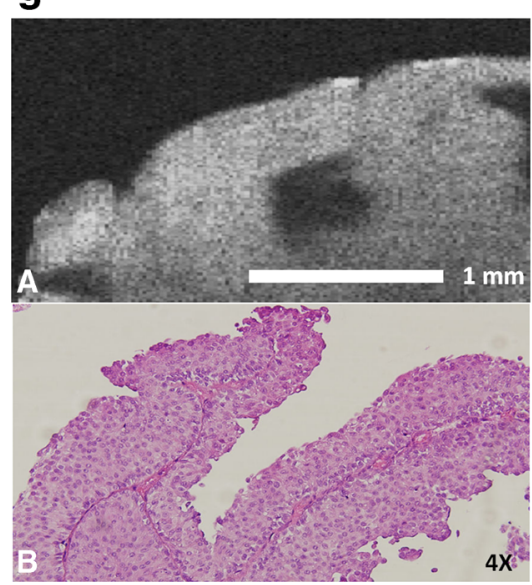

Fig. 3 (continued)

clinical study is needed to establish robust differentiation of melanoma from benign nevi.

Oral, laryngeal, and esophageal cancer

\section{Oral cancer}

SCC, accounting for $96 \%$ of all oral cancers, is mostly preceded by dysplasia presenting as white or red lesions on the oral mucosa (leukoplakia, erythroplakia). Currently, these potentially malignant lesions are biopsied or excised and therefore less suitable for screening of high-risk population. Only a few studies have been performed on OCT in the oral cavity. One of these studies included 143 healthy volunteers and demonstrated a varying thickness of epithelium depending on its location within the oral cavity. The largest thickness values were measured in the region of the buccal mucosa and the hard palate, whereas the thinnest epithelium was found at the floor of the mouth [23]. Wilders-Smith et al. imaged 50 patients with oral suspicious lesions with OCT, shown in Fig. 3c. After imaging, standard biopsy and histopathology were performed. Two investigators diagnosed the lesions blinded on OCT and histopathology subsequently. For detecting carcinoma in situ or SCC versus noncancer, sensitivity was 0.931 and specificity was 0.931; for detecting SCC versus all other pathologies, sensitivity was 0.931 and specificity was 0.973 [24]. Another study showed differences between normal oral mucosa, dysplasia and SCC scoring the OCT images on three indicators: epidermal layer thickness, standard deviation of an A-mode scan intensity profile in the epidermal layer, and the attenuation of light. However, the clinical value of this study is limited due to unclear methodology [25]. Recently, Adegun et al. measured the backscattered light intensity as a function of depth in OCT images of biopsy samples from the oral cavity. Hereby, they could differentiate dysplasia from normal control samples [26]. Overall, OCT seems to differentiate well between normal tissue and SCC.

\section{Laryngeal cancer}

Several studies in the human larynx have been performed. In a study of 82 patients undergoing surgery for various head and neck pathology, OCT provided information on epithelial layer thickness, integrity of the basement membrane (BM), and microstructural features. Whereas the normal epithelial thickness varied from 98 to $185 \mu \mathrm{m}$, the epithelial layer was thickened up to $300 \mu \mathrm{m}$ in hyperkeratotic lesions. In hyperkeratotic lesions, the BM on OCT images was still intact in contrary to early microinvasive SCC of the larynx, where disruption of the BM was seen on OCT images. Moreover, OCT images were comparable with conventional histopathology [27].

\section{Esophageal cancer}

Over the past two decades, the incidence of esophageal adenocarcinoma (AC) has risen considerably, especially in the distal esophagus and the esophagogastric junction. Several studies showed that gastro-esophageal reflux disease increases the risk of getting esophageal AC [28] by promoting the formation of Barret's esophagus (BE), a precursor of AC. At the moment, endoscopy and random taken biopsies are used to follow up patients with BE. Endoscopic OCT might be helpful in selecting suspicious areas in BE for further biopsy.

The use of OCT in imaging the esophagus and the esophagogastric junction has been widely studied. Ex-vivo studies showed that OCT can differentiate diverse layers in the esophageal wall [29] and can generate images corresponding to histology [30, 31]. Poneros et al. formulated different criteria for intestinal metaplasia on the basis of OCT images. When tested prospectively, these criteria had a sensitivity of $97 \%$ and a specificity of $92 \%$ [32]. Likewise, others acquired OCT images of the esophagus and stomach in 69 patients containing normal squamous muco$\mathrm{sa}, \mathrm{BE}$ and AC. These OCT images were accurately recognized by observers unaware of their site of origin, with an accuracy of $84.6 \%$ [33]. Isenberg determined the accuracy of endoscopic OCT in diagnosis of dysplasia in patients with BE. They reported an accuracy of $78 \%$ for the detection of dysplasia in BE. Main limitations of the study were the variability in endoscopists' accuracy rates, difficulty in real-time interpretation, and the need for refined criteria of dysplasia in endoscopic OCT imaging [34]. OCT of dysplasia was studied in more detail by Evens et al. They studied biopsy-correlated OCT images to establish OCT image characteristics able to differentiate intramucosal carcinoma (ICM) and high-grade dysplasia (HGD) from low-grade 
dysplasia, because ICM and HGD have a higher risk of developing into AC. There was a significant relationship between the histopathological diagnosis of IMC/HGD and the scores for each OCT image feature [35]. Recent improvements in endoscopic OCT made it possible to image larger areas such as the entire distal esophagus (approximately $6.0 \mathrm{~cm}$ ) with ultrahigh resolution [36, 37]. An example of a typical OCT image of the esophagus is given in Fig. 3d. With this approach, it may be possible to accurately define patients with dysplasia who are at risk for developing AC.

Genital and bladder cancer

\section{Vulvar cancer}

In the last 30 years, the incidence of vulvar intraepithelial neoplasia (VIN), a premalignant skin disorder that often causes pruritus, pain and psychosexual dysfunction, has increased more than $400 \%$ to approximately 2.5 cases per 100,000 women in the USA. The progression rate of VIN into VSCC is about $9 \%$ in untreated patients and $3.3 \%$ in patients after treatment. VIN is treated using conservative surgical excision, laser vaporization, or medical therapy. Patients are regularly examined to foresee occult invasion and check for possible new VIN lesions [38]. Definite diagnosis of a vulvar lesion of uncertain significance is obtained by punch biopsy. However, every attempt is made to avoid vulvar mutilation that may lead to psychosexual distress $[39,40]$. Hence, in the present workflow in the diagnosis and treatment of VIN, there is a clear need for non-invasive diagnostic tools.

In a study by Escobar et al., three patients with Paget's disease (a potential premalignant lesion) were imaged with OCT [41]. The authors observed clear irregularities in the epithelial layer and disruption of the basal membrane. Besides disruption of the basement membrane, OCT may be helpful in characterization of vulvar lesions by demonstrating differences in layer thickness and in the attenuation of light between different tissues. Data from our group in 16 patients with VIN show a significant difference in the thickness of the epidermal layer as well as in the attenuation of light between VIN lesions and healthy skin [10]. These differences probably occur because of the growth of neoplastic cells and changed nuclear/cytoplasma ratio in VIN lesions compared with healthy cells [11]. These data indicate the potential of OCT to distinguish between healthy and VIN lesions. In Fig. 3e, an example of an OCT image of a VIN lesion is shown.

\section{Cervical cancer}

Cervical cancer is generally preceded by intraepithelial neoplasia (CIN). Hence, the implementation of new imaging techniques that allow cheap, real-time, and non-invasive detection of premalignant abnormalities have the potential to improve the logistics and economics of screening programs for invasive cervical cancer [41, 42].

The diagnostic value of OCT in the detection of CIN has been studied by several groups. In 1999, the first ex vivo study on 32 cervical specimens concluded that an intact basement membrane - a feature of healthy epithelium in histology — can be seen with OCT [43]. The first in vivo studies were performed by Escobar et al. [41]. OCT images of patients with CIN I, II, and III lesions were directly compared to histology reports. All images of normal cervix showed a clear epithelial layer and a basal membrane that was defined as an interface between a brighter scattering (stroma) and a poorer scattering (epithelium) region in the OCT image. The authors concluded that this pattern presented normal squamous epithelium. In 16 of the 18 patients with CIN II and/or III, the images showed an unstructured homogenous area with highly backscattering region and fast attenuation of the signal; however, this was not quantified. This correlation between the intensity of the backscattering light from the epithelia of normal and abnormal tissue in the cervix, was also found by others [44]. To determine further accuracy of the OCT images, a grading scale was used to describe the OCT images: normal if a well-organized two-layered structure was seen with a sharp interface between the surface epithelium (squamous) and underlying layer (connective tissue); abnormal if the tissue was unstructured with no interface present and intermediate if irregularities on the images suggested artifacts or physiological conditions that did not meet the criteria. With this grading scale, sensitivity and specificity of OCT alone for $\geq$ CIN II lesions was 56 and $59 \%$, respectively [45].

If patients with positive cervix cytology for dysplastic cells undergo colposcopy, OCT might have the potential to predict if a specific spot seen with colposcopy is CIN I, II, III or invasive cancer. In this setting, Liu investigated OCT imaging in colposcopy. OCT decreased the sensitivity to detect $\geq$ CIN II lesions form 63 to $36 \%$; however, specificity increased from 83 to $93 \%$ [46]. To improve clinical analysis, Lee looked at the degrees of circular polarization caused by the scattering changes induced by CIN. A linear fitting procedure was used to quantify the attenuation of the degrees-of-polarization signal. This approach resulted in sensitivity and specificity to detect CIN of 94.7 and $71.2 \%$, respectively [47]. An OCT image of a CIN I lesion is shown in Fig. 3f. Further improvements in OCT resolution are currently tested to improve accuracy of OCT for diagnosing cervical cancer and CIN.

\section{Bladder cancer}

In nondiseased tissue, the three anatomic layers of the bladder wall (urothelium, lamina propria, and muscularis propria) can 
be well distinguished with OCT $[48,49]$. Hermes et al. evaluated OCT in 142 human bladder specimens ex vivo and demonstrated that OCT could discriminate between normal, CIS and invasive transitional cell carcinoma (TCC) with a sensitivity of $83.8 \%$ and a specificity of $78.1 \%$. None of the CIS or TCC samples was classified as normal tissue based on the OCT image (no false-negatives), 6 samples of normal tissue were classified as TCC (false-positive rate $5.7 \%$ ), and 24 samples could not be classified (16.9\%) [50]. Two groups investigated the diagnostic accuracy of cystoscopic applied OCT. Manyak et al. classified bladder tissue samples as benign or malignant with an overall sensitivity and specificity of 100 and $89 \%$, respectively. Ten malignancies were classified by OCT as invasive $(\geq \mathrm{T} 1)$, of which nine were confirmed by histology [51]. Lerner et al. showed that differentiation of bladder tumors confined to the mucosa (Ta) was possible with a sensitivity of $90 \%$ and a specificity of $89 \%$. For differentiation of $\mathrm{T} 1$ and $\mathrm{T} 2$ tumors, sensitivity was 75 and $100 \%$, while specificity was 97 and $90 \%$ [52]. False-positive findings could generally be explained by inflammatory lesions of the bladder [51].

Lingley-Papadopoulos et al. developed an automated algorithm that allows recognition of texture within an OCT image to provide the urologist with a diagnosis. This algorithm was able to differentiate benign and malignant bladder tissue with a sensitivity of $92 \%$ and a specificity of $62 \%$ [53].

Since real-time high-resolution OCT images can be obtained during cystoscopy, the technique may especially be useful for guidance of biopsy procedures and staging of suspected tissue areas within the bladder. In Fig. 3g, an OCT image of a papillary carcinoma of the bladder is shown.

\section{Discussion and conclusions}

OCT is an optical diagnostic tool that aims to predict in vivo histopathologic diagnosis in a non-invasive way. It produces real-time high-resolution images comparable with histopathology. Several studies have shown that OCT can be used to distinguish healthy skin from NMSC. For detection of melanoma lesions, however, the accuracy is still limited. In the oral cavity and larynx, OCT is able to distinguish between normal tissue and SCC. In addition, OCT can give information about tissue thickness and basement membrane integrity. Differentiation between dysplasia and normal can still be improved. In the esophagus, large areas with high resolution can be imaged allowing tissue characterization of dysplasia as well as tumor tissue. For vulva lesions, OCT proved to be able to differentiate between healthy tissue and VIN lesions, while in the cervix OCT allowed differentiation between normal cervical tissue and CIN. However, OCT is not capable of distinguishing different CIN grades. Bladder OCT so far has shown the potential to differentiate grade and stage in small populations but it needs a larger population study to provide definite answers.

Future perspectives

OCT holds the potential to provide functional optical biopsies of epithelial cancers by combining imaging with quantification of physiological functional parameters, e.g., perfusion and oxygenation or cellular organization. This can be achieved either by advanced analysis of the OCT signal itself $[54,55]$ or by combining OCT with other imaging modalities such as Raman spectroscopy (RS) [56] or fluorescence spectroscopy [57]. Analysis of the spatial and temporal changes of the OCT signal allows determination of the optical attenuation coefficient (which is related to tissue organization) and blood perfusion. We have demonstrated that the attenuation coefficient discriminates between normal and (pre)cancerous lesions in vulva [10], bladder [9], and kidney [7, 8]. Advanced implementations of OCT use light that is extended from the near infrared to the visible wavelengths, allowing quantification of hemoglobin concentrations [58] and oxygen saturation ultimately allowing to map oxygen metabolism of individual locations in the lesion. Complementary information on biochemical composition can be obtained by combining OCT with RS. In that way, RS can estimate the molecular composition of tissue, while OCT can produce images. The use of OCT in combination with other techniques can hereby assist in screening and eventually even diagnose malignancies non-invasively.

Acknowledgments The authors would like to acknowledge Swanson [18], Wilder-Smith [24], Suter [36], and Gallwas [42] and their publishers for providing them OCT figures of their studies.

Open Access This article is distributed under the terms of the Creative Commons Attribution License which permits any use, distribution, and reproduction in any medium, provided the original author(s) and the source are credited.

\section{References}

1. Siegel R, Naishadham D, Jemal A (2012) Cancer statistics, 2012. CA Cancer J Clin 62(1):10-29

2. Izatt JA, Hee MR, Swanson EA, Lin CP, Huang D, Schuman JS, Puliafito CA, Fujimoto JG (1994) Micrometer-scale resolution imaging of the anterior eye in vivo with optical coherence tomography. Arch Ophthalmol 112(12):1584-1589

3. Hee MR, Izatt JA, Swanson EA, Huang D, Schuman JS, Lin CP, Puliafito CA, Fujimoto JG (1995) Optical coherence tomography of the human retina. Arch Ophthalmol 113(3):325-332

4. Drexler W, Fugimoto J (eds) (2008) Optical coherence tomography: technology and applications, 2008th edn. Springer, New York

5. van Zeeburg EJ, Cereda MG, van der Schoot J, Pertile G, van Meurs JC (2011) Early perfusion of a free RPE-choroid graft in patients with exudative macular degeneration can be imaged with spectral domain-OCT. Invest Ophthalmol Vis Sci 52(8):58815886 
6. Srinivasan VJ, Radhakrishnan H, Lo EH, Mandeville ET, Jiang JY, Barry S, Cable AE (2012) OCT methods for capillary velocimetry. Biomed Opt Express 3(3):612-629

7. Barwari $\mathrm{K}$ et al (2010) Advanced diagnostics in renal mass using optical coherence tomography: a preliminary report. J Endourol 25(2):311-315, 2011Feb

8. Barwari K, de Bruin DM, Faber DJ, van Leeuwen TG, de la Rosette JJ, Laguna MP (2012) Differentiation between normal renal tissue and renal tumours using functional optical coherence tomography: a phase I in vivo human study. BJU Int 110(8PtB): E415-E420, 2012Oct

9. Cauberg ECC et al (2010) Quantitative measurement of attenuation coefficients of bladder biopsies using optical coherence tomography for grading urothelial carcinoma of the bladder. $\mathrm{J}$ Biomed Opt 15(6):066013, 2010Nov-Dec

10. Wessels R, de Bruin DM, Faber DJ, van Boven HH, Vincent AD, van Leeuwen TG, van Beurden M, Ruersa TJ (2012) Optical coherence tomography in vulvar intraepithelial neoplasia. J Biomed Opt 17(11):116022

11. Bista RK, Uttam S, Wang P, Staton K, Choi S, Bakkenist CJ, Hartman DJ, Brand RE, Liu Y (2011) Quantification of nanoscale nuclear refractive index changes during the cell cycle. J Biomed Opt 16(7):070503

12. Madan V, Lear JT, Szeimies RM (2010) Non-melanoma skin cancer. Lancet 375(9715):673-685

13. Neville JA, Welch E, Leffell DJ (2007) Management of nonmelanoma skin cancer in 2007. Nat Clin Pract Oncol 4(8):462-469

14. Gambichler T, Orlikov A, Vasa R, Moussa G, Hoffmann K, Stucker M, Altmeyer P, Bechara FG (2007) In vivo optical coherence tomography of basal cell carcinoma. J Dermatol Sci 45(3):167-173

15. Jorgensen TM, Tycho A, Mogensen M, Bjerring P, Jemec GB (2008) Machine-learning classification of non-melanoma skin cancers from image features obtained by optical coherence tomography. Skin Res Technol 14(3):364-369

16. Mogensen M, Joergensen TM, Nurnberg BM, Morsy HA, Thomsen JB, Thrane L, Jemec GB (2009) Assessment of optical coherence tomography imaging in the diagnosis of non-melanoma skin cancer and benign lesions versus normal skin: observer-blinded evaluation by dermatologists and pathologists. Dermatol Surg 35(6):965-972

17. Mogensen M, Nurnberg BM, Forman JL, Thomsen JB, Thrane L, Jemec GB (2009) In vivo thickness measurement of basal cell carcinoma and actinic keratosis with optical coherence tomography and 20-MHz ultrasound. Br J Dermatol 160(5):1026-1033

18. Olmedo JM, Warschaw KE, Schmitt JM, Swanson DL (2006) Optical coherence tomography for the characterization of basal cell carcinoma in vivo: a pilot study. J Am Acad Dermatol 55(3):408-412

19. Olmedo JM, Warschaw KE, Schmitt JM, Swanson DL (2007) Correlation of thickness of basal cell carcinoma by optical coherence tomography in vivo and routine histologic findings: a pilot study. Dermatol Surg 33(4):421-425

20. Strasswimmer J, Pierce MC, Park BH, Neel V, de Boer JF (2004) Polarization-sensitive optical coherence tomography of invasive basal cell carcinoma. J Biomed Opt 9(2):292-298

21. de Giorgi SM, Massi D, Mavilia L, Cappugi P, Carli P (2005) Possible histopathologic correlates of dermoscopic features in pigmented melanocytic lesions identified by means of optical coherence tomography. Exp Dermatol 14(1):56-59

22. Gambichler T, Regeniter P, Bechara FG, Orlikov A, Vasa R, Moussa G, Stucker M, Altmeyer P, Hoffmann K (2007) Characterization of benign and malignant melanocytic skin lesions using optical coherence tomography in vivo. J Am Acad Dermatol 57(4):629-637

23. Prestin S, Rothschild SI, Betz CS, Kraft M (2012) Measurement of epithelial thickness within the oral cavity using optical coherence tomography. Head Neck 34(12):1777-1781, 2012Dec
24. Wilder-Smith P, Lee K, Guo S, Zhang J, Osann K, Chen Z, Messadi D (2009) In vivo diagnosis of oral dysplasia and malignancy using optical coherence tomography: preliminary studies in 50 patients. Lasers Surg Med 41(5):353-357

25. Tsai MT, Lee CK, Lee HC, Chen HM, Chiang CP, Wang YM, Yang CC (2009) Differentiating oral lesions in different carcinogenesis stages with optical coherence tomography. J Biomed Opt 14(4):044028

26. Adegun OK, Tomlins PH, Hagi-Pavli E, Bader DL, Fortune F (2012) Quantitative optical coherence tomography of fluid-filled oral mucosal lesions. Lasers Med Sci 27(4):795-804, 2012Jul

27. Wong BJ, Jackson RP, Guo S, Ridgway JM, Mahmood U, Su J, Shibuya TY, Crumley RL, Gu M, Armstrong WB, Chen Z (2005) In vivo optical coherence tomography of the human larynx: normative and benign pathology in 82 patients. Laryngoscope 115(11):1904-1911

28. Lagergren J, Bergstrom R, Lindgren A, Nyren O (1999) Symptomatic gastroesophageal reflux as a risk factor for esophageal adenocarcinoma. N Engl J Med 340(11):825-831

29. Cilesiz I, Fockens P, Kerindongo R, Faber D, Tytgat G, Ten Kate F, Van Leeuwen T (2002) Comparative optical coherence tomography imaging of human esophagus: how accurate is localization of the muscularis mucosae? Gastrointest Endosc 56(6):852-857

30. Cobb MJ, Hwang JH, Upton MP, Chen Y, Oelschlager BK, Wood DE, Kimmey MB, Li X (2010) Imaging of subsquamous Barrett's epithelium with ultrahigh-resolution optical coherence tomography: a histologic correlation study. Gastrointest Endosc 71(2):223-230

31. Pitris C, Jesser C, Boppart SA, Stamper D, Brezinski ME, Fujimoto JG (2000) Feasibility of optical coherence tomography for high-resolution imaging of human gastrointestinal tract malignancies. J Gastroenterol 35(2):87-92

32. Poneros JM, Brand S, Bouma BE, Tearney GJ, Compton CC, Nishioka NS (2001) Diagnosis of specialized intestinal metaplasia by optical coherence tomography. Gastroenterology 120(1):7-12

33. Zuccaro G, Gladkova N, Vargo J, Feldchtein F, Zagaynova E, Conwell D, Falk G, Goldblum J, Dumot J, Ponsky J, Gelikonov G, Davros B, Donchenko E, Richter J (2001) Optical coherence tomography of the esophagus and proximal stomach in health and disease. Am J Gastroenterol 96(9):2633-2639

34. Isenberg G, Sivak MV Jr, Chak A, Wong RC, Willis JE, Wolf B, Rowland DY, Das A, Rollins A (2005) Accuracy of endoscopic optical coherence tomography in the detection of dysplasia in Barrett's esophagus: a prospective, double-blinded study. Gastrointest Endosc 62(6):825-831

35. Evans JA, Poneros JM, Bouma BE, Bressner J, Halpern EF, Shishkov M, Lauwers GY, Mino-Kenudson M, Nishioka NS, Tearney GJ (2006) Optical coherence tomography to identify intramucosal carcinoma and high-grade dysplasia in Barrett's esophagus. Clin Gastroenterol Hepatol 4(1):38-43

36. Suter MJ, Vakoc BJ, Yachimski PS, Shishkov M, Lauwers GY, Mino-Kenudson M, Bouma BE, Nishioka NS, Tearney GJ (2008) Comprehensive microscopy of the esophagus in human patients with optical frequency domain imaging. Gastrointest Endosc 68(4):745-753

37. Vakoc BJ, Shishko M, Yun SH, Oh WY, Suter MJ, Desjardins AE, Evans JA, Nishioka NS, Tearney GJ, Bouma BE (2007) Comprehensive esophageal microscopy by using optical frequencydomain imaging (with video). Gastrointest Endosc 65(6):898-905

38. Van Seters M, van Beurden M, de Craen AJ (2005) Is the assumed natural history of vulvar intraepithelial neoplasia III based on enough evidence? A systematic review of 3322 published patients. Gynecol Oncol 97(2):645-651

39. Andersen BL, Turnquist D, LaPolla J, Turner D (1988) Sexual functioning after treatment of in situ vulvar cancer: preliminary report. Obstet Gynecol 71(1):15-19 
40. Judson PL, Habermann EB, Baxter NN, Durham SB, Virnig BA (2006) Trends in the incidence of invasive and in situ vulvar carcinoma. Obstet Gynecol 107(5):1018-1022

41. Escobar PF, Belinson JL, White A, Shakhova NM, Feldchtein FI, Kareta MV, Gladkova ND (2004) Diagnostic efficacy of optical coherence tomography in the management of preinvasive and invasive cancer of uterine cervix and vulva. Int J Gynecol Cancer 14(3):470-474

42. Gallwas JK, Turk L, Stepp H, Mueller S, Ochsenkuehn R, Friese K, Dannecker C (2011) Optical coherence tomography for the diagnosis of cervical intraepithelial neoplasia. Lasers Surg Med 43(3):206-212

43. Pitris C, Goodman A, Boppart SA, Libus JJ, Fujimoto JG, Brezinski ME (1999) High-resolution imaging of gynecologic neoplasms using optical coherence tomography. Obstet Gynecol 93(1):135-139

44. Zuluaga AF, Follen M, Boiko I, Malpica A, Richards-Kortum R (2005) Optical coherence tomography: a pilot study of a new imaging technique for noninvasive examination of cervical tissue. Am J Obstet Gynecol 193(1):83-88

45. Escobar PF, Rojas-Espaillat L, Tisci S, Enerson C, Brainard J, Smith J, Tresser NJ, Feldchtein FI, Rojas LB, Belinson JL (2006) Optical coherence tomography as a diagnostic aid to visual inspection and colposcopy for preinvasive and invasive cancer of the uterine cervix. Int J Gynecol Cancer 16(5):1815-1822

46. Liu Z, Belinson SE, Li J, Yang B, Wulan N, Tresser NJ, Wang C, Mohr M, Zhang L, Zhou Y, Weng L, Wu R, Belinson JL (2010) Diagnostic efficacy of real-time optical coherence tomography in the management of preinvasive and invasive neoplasia of the uterine cervix. Int J Gynecol Cancer 20(2):283-287

47. Lee SW, Yoo JY, Kang JH, Kang MS, Jung SH, Chong Y, Cha DS, Han KH, Kim BM (2008) Optical diagnosis of cervical intraepithelial neoplasm (CIN) using polarization-sensitive optical coherence tomography. Opt Express 16(4):2709-2719

48. Jesser CA, Boppart SA, Pitris C, Stamper DL, Nielsen GP, Brezinski ME, Fujimoto JG (1999) High resolution imaging of transitional cell carcinoma with optical coherence tomography: feasibility for the evaluation of bladder pathology. Br J Radiol 72(864):1170-1176
49. Tearney GJ, Brezinski ME, Southern JF, Bouma BE, Boppart SA, Fujimoto JG (1997) Optical biopsy in human urologic tissue using optical coherence tomography. J Urol 157(5):1915-1919

50. Hermes B, Spoler F, Naami A, Bornemann J, Forst M, Grosse J, Jakse G, Knuchel R (2008) Visualization of the basement membrane zone of the bladder by optical coherence tomography: feasibility of noninvasive evaluation of tumor invasion. Urology 72(3):677-681

51. Manyak MJ, Gladkova ND, Makari JH, Schwartz AM, Zagaynova EV, Zolfaghari L, Zara JM, Iksanov R, Feldchtein FI (2005) Evaluation of superficial bladder transitional-cell carcinoma by optical coherence tomography. J Endourol 19(5):570-574

52. Goh AC, Tresser NJ, Shen SS, Lerner SP (2008) Optical coherence tomography as an adjunct to white light cystoscopy for intravesical real-time imaging and staging of bladder cancer. Urology 72(1):133-137

53. Lingley-Papadopoulos CA, Loew MH, Manyak MJ, Zara JM (2008) Computer recognition of cancer in the urinary bladder using optical coherence tomography and texture analysis. J Biomed Opt 13(2):024003

54. Faber D, van der Meer F, Aalders M, van Leeuwen T (2004) Quantitative measurement of attenuation coefficients of weakly scattering media using optical coherence tomography. Opt Express 12(19):4353-4365

55. Faber DJ, van Leeuwen TG (2009) Are quantitative attenuation measurements of blood by optical coherence tomography feasible? Opt Lett 34(9):1435-1437

56. Patil CA, Kalkman J, Faber DJ, Nyman JS, van Leeuwen TG, Mahadevan-Jansen A (2011) Integrated system for combined Raman spectroscopy-spectral domain optical coherence tomography. J Biomed Opt 16(1):011007

57. Robles FE, Wilson C, Grant G, Wax A (2011) Molecular imaging true-colour spectroscopic optical coherence tomography. Nat Photonics 5(12):744-747

58. Bosschaart N, Faber DJ, van Leeuwen TG, Aalders MC (2011) In vivo low-coherence spectroscopic measurements of local hemoglobin absorption spectra in human skin. J Biomed Opt 16(10):100504 